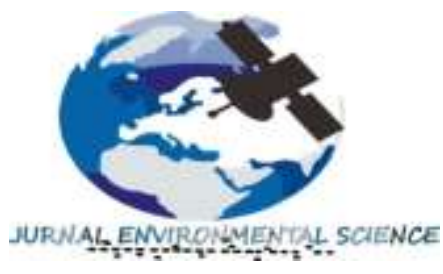

Jurnal Environmental Science

Volume 3 Nomor 2 April 2021

p-ISSN : 2654-4490 dan e-ISSN : 2654-9085

Homepage at : ojs.unm.ac.id/JES

E-mail:jes@unm.ac.id

\title{
EKSISTENSI KERJA PANDAI BESI TRADISIONAL MEMASUKI ERA REVOLUSI INDUSTRI DI KABUPATEN SIDENRENG RAPPANG
}

\author{
Cenceng ${ }^{1}$, Ramli Umar ${ }^{2}$, Syukri Nyompa ${ }^{3}$ \\ Jurusan Geografi, Fakultas Matematika Dan Ilmu pengetahuan Alam \\ Universitas Negri Makassar, Indonesia \\ Email: cencengwadi038@gmail.com ${ }^{1}$,ramliumar707@yahoo.com ${ }^{2}$, sukri_nyompa@yahoo.co.id ${ }^{3}$
}

\begin{abstract}
The objectives of this study were: 1) To determine the working characteristics of traditional blacksmiths in Sidenreng Rappang Regency. 2) to find out what are the factors that influence the existence of traditional blacksmiths in facing the industrial era. 3) to find out how the traditional blacksmith survived in the industrial revolution era in Sidenreng Rappang district. The type of research used is descriptive quantitative research, which is used to describe the phenomenon of social reality found in people who are used as objects or targets in research that seeks to draw that reality to the surface as a feature, nature, character, sign, or description of the situation, situation model, or problem specific phenomenon. The results showed that the working characteristics of blacksmiths in Massepe Village, namely for the most dominant age of the respondents, were found in the age group of 50 years and over by 36\%, who were generally male, where working time started on Monday-Saturday at 08:00. -16: 00 with an income of Rp. 500,000-2,500,000. The factors affecting the work of blacksmiths in Massepe Village are Products, where seasonal factors, quality and size are 100\% very influencing the existence of blacksmiths in entering the revolutionary era except for the color factor, in terms of promotion the very influential factor is marketing in traditional markets. at 100\%. For the price, the relatively cheap price factor is very influential by $81 \%$ and also the addition of credit has a positive influence on blacksmith craftsmen.
\end{abstract}

Keywords: Existence, Blacksmith, Industrial Revolution Era, Massepe Village

\begin{abstract}
ABSTRAK
Tujuan penelitian ini: 1) Yaitu untuk mengetahui Karakteristik Kerja pandai Besi Tradisional di Kabupaten Sidenreng Rappang. 2) untuk mengetahui apa saja Faktor-Faktor Yang Mempengaruhi Eksistensi Kerja Pandai Besi Tradisional Dalam Menghadapi Era Industri. 3) untuk mengetahui bagaimana Pandai Besi Tradisional Bisa Bertahan di Era Revolusi Industri di kabupaten Sidenreng Rappang. Jenis penelitian yang digunakan adalah penelitian Kuantitatif deskriptif yaitu digunakan untuk menggambarkan fenomena realita sosial yang dijumpai pada masyarakat yang dijadikan objek atau sasaran dalam penelitian yang berupaya menarik kenyataan itu ke atas permukaan sebagai suatu ciri, sifat, karakter, tanda, atau deskripsi mengenai keadaan, situasi, model, ataupu fenomena masalah tertentu. Hasil penelitian menunjukkan bahwa karakteristik kerja pandai besi di Kelurahan Massepe yaitu untuk umur responden yang paling dominan jumlahnya dijumpai pada kelompok umur 50 tahun ke atas sebesar 36\% yang umumnya berjenis kelamin laki-laki dimana waktu kerjanya dimulai pada hari senin-sabtu jam 08:00-16:00 dengan pendapatan Rp. 500.000-2.500.000. faktor-faktor yang mempengaruhi kerja pandai besi di Kelurahan Massepe yaitu Produk, dimana faktor musiman, kualitas dan ukuran sebesar 100\% sangat mempengaruhi eksistensi kerja pandai besi dalam memasuki era revolusi kecuali faktor warna, dari segi promosi faktor yang sangat berpengaruh yaitu pemasaran di pasar tradional sebesar $100 \%$. Untuk harga, faktor harga yang relative murah sangat berpengaruh sebesar $81 \%$ dan juga penambahan kredit memberikan pengaruh positif bagi pengrajin pandai besi.
\end{abstract}

Kata Kunci: Eksistensi, Pandai besi, Era Revolusi Industri, Kelurahan Massepe 


\section{PENDAHULUAN}

Eksistensi merupakan suatu proses pergerakan untuk menjadi ada, dan kemudian selanjutnya dilakukan suatu hal agar tetap masih menjadi ada. Sedangkan dibidang ekonomi sendiri biasanya industry, eksisytensi dapat diartikan sebagai oprasi kegiatanindusytri yang dimaksudkan pada suatu keadaan dimana perkembangan yang terus tetap naik Graham (2005) dalam Rickho (2009). Usaha pandai besi merupakan usaha rumh tangga yang bergerak di bidang pengolahan besi menjadi peralatan rumah tangga, perytanian dan lainnya, usaha pandai besi juga disebut sebagai kerajinan masyarakat dalam bentuk barang-barang yang berasal dari besi untuk tujuan perekonomian atau sumber mata pencarian (Sudirman, 2004).

Perkerjaan pandai besi adalah suatu profesi pekerjaan yang sudah lama dilakukan atau ditekuni dan mempunyai peminat yang cukup banyak, namun masih terdapat ada beberapa problem yang sering dijumpai oleh para pengrajin pandai besi sering dalam perkembangan era industri yang menggeser produk hasil kerajinan masyarakat di indonesi. Di Kabupaten Sidenreng Rappang terdapat kegiatan masyarakat yang dapat dikategorikan sebagai industri kecil yang dikelola baik secara perorangan maupun secara kelompok. Pandai besi di massepe dahulu merupakan tempat membuat dan memproduksi alat-alat peperangan yang di butuhkan tentara addatuang Sidenreng dan kerajaan kerajaanlainya seperti senjata, tombak, badik, parang, anak panah dan lain-lain, namun setelah era peperangan berlalu maka masyarakat setempat pun mengembangkan usahanya yaitu memproduksi alat - alat perang tetapi meniptakan inovasi-inovasi baru multifungsi yang di butuhkan dalam keperluan rumah tangga dan alat-alat pertanian serta perkebunan seperti alat bayak tanah, cangkul, linggis, parang, dan lain-lain.

Berdasarkan data Dinas Perindustrian jumlah tenaga kerja pandai besi sebanyak 288 Orang dan 74 Pandai besi di Massepe. Industri kerajinan besi ini cukup terkenal di Sulawesi Selatan, bukan hanya di Sulawesi Selatan saja tetapi pandai besi ini sudah terkenal di provinsi lain seperti Kalimantan bahkan sampai Papua. Pandai besi (panrebessi) merupakan tukang tempa logam yang mengolah bahan mentah besi menjadi bahan jadi seperti peralatan rumah tangga dan alat-alat pertanian. Kadis Perindagkop UKM Sidrap, Bapak Hamka Lokki melalui Kabid Perindustrian, Bapak Sudarmin di Kantornya, Senin, 29 Oktober, mengemukakan bahwa usaha pandai besi ini merupakan suatu ikon yang dimiliki serta menjadi kebanggaan pemerintah dan masyarakat kabupaten Sidrap (Rahmi, 2018).

Dari kondisi tersebut, beberapa faktor yang diyakini dapat mempengaruhi produktivitas tenaga kerja, yakni upah, pengalaman kerja, umur, permintaan dan penjualan barang, keterampilan, bahan baku, teknologi, motivasi kerja, dan jam kerja. Dalam penelitan ini, hanya memilih faktor upah, pengalaman kerja, dan umur, hal ini dikarenakan keterbatasan waktu yang dimiliki peneliti, sehingga peneliti hanya terfokus pada ketiga variabel tersebut.

Dari penjelasan di atas, maka perlu dilakukan penelitian tentang "Eksistensi Kerja Pandai Besi Tradisional dalam Menghadapi Era Industri di Kabupaten Sidenreng Rappang”. Dengan melakukan eksistensi kerja pandai besi di kelurahan massepe, maka peneliti dan pembaca mengetahui eksistensi kerja pandai besi di kelurahan massepe. Penelitian ini bertujuan: 1) Yaitu untuk mengetahui Karakteristik Kerja pandai Besi 
Tradisional di Kabupaten Sidenreng Rappang. 2) Apa saja Faktor-Faktor Yang Mempengaruhi Eksistensi Kerja Pandai Besi Tradisional Dalam Menghadapi Era Industri. 3) Bagaimana Pandai Besi Tradisional Bisa Bertahan di Era Revolusi Industri di kabupaten Sidenreng Rappang.

\section{METODE PENELITIAN}

Jenis penelitian yang digunakan adalah penelitian kulitatif deskriptif yaitu yang digunakan untuk menggambarkan dan menganalisis suatu hasil penelitian secara sistematis tentang Eksistensi Kerja Pandai Besi Tradisional dalam Menghadapi Era Industri di Kabupaten Sidenreng Rappang. Adapun lokasi penelitian ini adalah di kelurahan Massepe kecamatan tellu limpo'e Kabupaten Sidenreng Rappang.

Populasi dalam penelitian ini yaitu semua sampel yang ada di kelurahan Massepe sebanyak 74 pandai besi. Dalam penelitian ini teknik pengambilan sampel yang sigunakan adalah purposive sampling. Purposive adalah penelitian akan memilih informasi dipandang paling tahu, sehingga kemungkinan pilihan informasi dapat berkembang sesuai kebutuhan dan kemantapan penelitian untuk memproleh data". Teknik Pengambilan informasi menggunakan purposive sampling karena dipandang lebih mampu menangkap kelengkapan dan kedalaman data didalam menghadapi realitas yang tidak tunggal (sugiyono, 2006).

Desain penelitian adalah rencagan kegiatan atau proses yang dilakukan dalam penelitian, mulai dari perumusan masalah sampai perum usan kesimpulan hasil penelitian dengan menggunakan langkah-langkah metode ilmiah sesuai rencangan metodologi pada disiplin ilmu tertentu. Tahap-tahap desain penelitian yang akan dilakukan adalah sebagai berikut:

1. Tahap Perencanaan

Menarik dan menentukan permasalahan pada penelitian. Setelah itu disusun kerangka konseptual yang berhubungan dengan masalah tersebut berdasarkan kajian teori dari berbagai literature. Tujuan untuk memperoleh landasan atau kerangka berpikir, guna pengembangan presepsi penelitian.

2. Tahap Pelaksanan

Melakukan tahaap akhir yang akan dilaksanakan meliputi penyusunan konsep laporan penelitian, pengetikan dan selanjutnya di konsultasikan kepada dosen pembimbing.

Adapun teknik penggumpulan data yang digunakan dalam penelitian ini sebagai berikut:

1. Observasi

Metode atau cara-cara yang menganalisis dan mengadakan pencatatan secara sistematis mengenai tingkah laku dengan melihat atau mengamati individu atau kelompok secara langsung atau pengumpulan data yang bersumber dari sampel (responden).

2. Wawancara

Wawancara merupakan suatu pertanyaan yang diberikan kepada narasumber dan pewawancara yang bertujuan untuk mendapatkan informasi atau data dengan cara melontarkan pertanyaan-pertanyaan.

3. Quistioner

Menyebarkan daftar pertanyaan tertulis untuk mendapatkan yang dapat mendukung penelitian, dengan alternatif jawaban yang dibagikan kepada responden yaitu seluruh perajin pandai besi di Kabupaten Sidenreng Rappang.

Metode yang digunakan dalam penelitian ini adalah kuantitatif deskeriptif yang dianalisis dalam bentuk table frekuensi. 


\section{HASIL DAN PEMBAHASAN}

Kabupaten Sidenreng Rappang atau yang dikenal dengan Kabupaten Sidrap merupakan salah satu Kabupaten di Provinsi Sulawesi Selatan yang terletak kira-kira $183 \mathrm{~km}$ sebelah utara kota Makassar (Ibu kota provinsi Sulawesi Selatan). Secara astronomis, Kabupten Sidrap terletak antara $3^{\circ} 43-4^{\circ} 09$ lintang selatan dan $119^{\circ} 41-120^{\circ} 10$ bujur timur. Wilayah administratif Kabupaten Sidrap terbagi dalam 11 kecamatan dan 106 desa/kelurahan (68 kelurahan dan 38 desa ) dengan luas 189.808,70 km2 jumlah sungai yang melintasi Kabupaten Sidrap sebanyak 38 aliran. Secara administratif Kelurahan Massepe merupakan bagian dari wilayah Kecamatan Tellu Limpoe Kabupaten Sidenreng Rappang yang terletak 11,0 Km dari Ibu kota Kabupaten Sidenreng Rappang, atau 3,0 Km dari Ibu kota Kecamatan dengan luas wilayah $1.138,1 \mathrm{Km}^{2}$ (BPS, Kabupaten Sidrap, 2017).

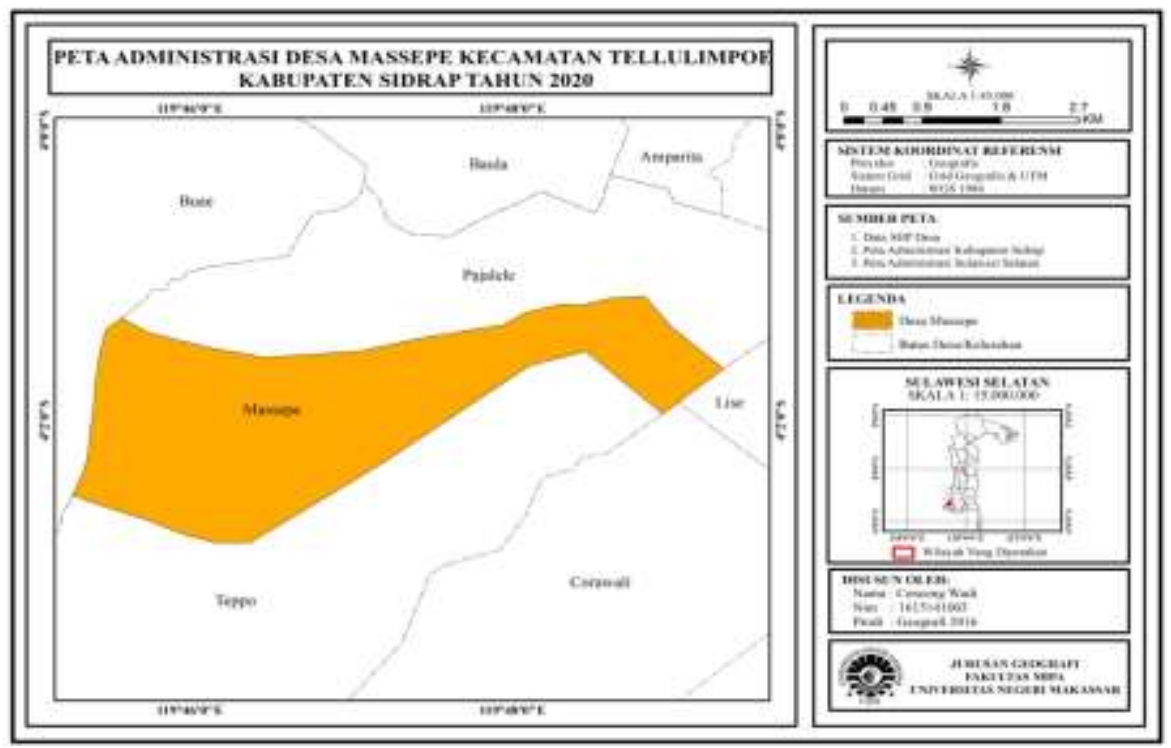

Gambar 1. Peta Administrasi Kelurahan Massepe Kecamatan Tellu Limpo'e Tahun 2020

\section{Hasil Penelitian}

1. Krakteristik Kerja Pandai Besi Tradisional di Kabupaten Sidenreng Rappang. Berikut penyajian data hasil penelitian berdsarkan kelompok umur, jenis kelamin, masa kerja, dan pendapatan:

Tabel 1 Kerakteristik kerja pandai besi menurut umur di Kabupaten Sidenreng Rappang Kecamatan Tellu Limpoe.

\begin{tabular}{cccc}
\hline No & Usia Responden (tahun) & Frekuensi & Presentase (\%) \\
\hline $\mathbf{1}$ & $20-24$ & 4 & 5 \\
$\mathbf{2}$ & $25-29$ & 1 & 1 \\
$\mathbf{3}$ & $30-34$ & 11 & 15 \\
$\mathbf{4}$ & $35-39$ & 10 & 14 \\
$\mathbf{5}$ & $40-44$ & 8 & 11 \\
$\mathbf{6}$ & $45-49$ & 13 & 18 \\
$\mathbf{7}$ & $>50$ & 27 & 36 \\
& Jumlah & 24 & 100 \\
\hline
\end{tabular}

Sumber: Data primer diolah, 2020. 
Tabel 2 Disrribusi Pandai Besi Menurut Jenis Kelamin di Massepe Kecamatan Tellu Limpoe Kabupaten Sidenreng Rappang

\begin{tabular}{cccc}
\hline No & Jenis Kelamin & Frekuensi & $\begin{array}{c}\text { Presentase } \\
(\boldsymbol{\%})\end{array}$ \\
\hline $\mathbf{1}$ & Laki-Laki & 74 & 100 \\
$\mathbf{2}$ & Perempuan & 0 & 0 \\
& Jumlah & 74 & 100 \\
\hline
\end{tabular}

Sumber: Data primer diolah, 2020.

Tabel 3 Distribusi Waktu Kerja Penrajin Pandai Besi Tradisional di Massepe Kecamatan Tellu Limpoe Kabupaten Sidenreng Rappang

\begin{tabular}{|c|c|c|c|}
\hline No & Jam Kerja & Frekuensi & $\begin{array}{c}\text { Presentase } \\
(\%)\end{array}$ \\
\hline 1 & $\begin{array}{l}\text { Senin s/d Sabtu } \\
07.00 \mathrm{~s} / \mathrm{d} 16.00\end{array}$ & 28 & 38 \\
\hline 2 & $\begin{array}{l}\text { Senin s/d Sabtu } \\
07.00 \mathrm{~s} / \mathrm{d} 17.00\end{array}$ & 1 & 1 \\
\hline 3 & $\begin{array}{l}\text { Senin s/d Sabtu } \\
08.00 \mathrm{~s} / \mathrm{d} 16.00\end{array}$ & 41 & 55 \\
\hline 4 & $\begin{array}{l}\text { Senin s/d Sabtu } \\
08.00 \mathrm{~s} / \mathrm{d} 17.00\end{array}$ & 2 & 3 \\
\hline 5 & $\begin{array}{l}\text { Senin s/d Sabtu } \\
15.00 \mathrm{~s} / \mathrm{d} 10.00\end{array}$ & 2 & 3 \\
\hline & Jumlah & 74 & 100 \\
\hline
\end{tabular}

Sumber: Data Primer diolah 2020

Tabel 4. Penghasilan Pandai Besi Per Bulan

\begin{tabular}{cccc}
\hline No. & Pendapatan/Bulan & Frekuensi & Presentase (\%) \\
\hline 1 & $500.000-2.500 .000$ & 43 & 58 \\
2 & $2.500 .000-5.000 .000$ & 15 & 20 \\
3 & $5.00 .000-10.000 .000$ & 14 & 19 \\
4 & $>10.000 .000$ & 2 & 3 \\
\hline & Jumlah & $\mathbf{7 4}$ & $\mathbf{1 0 0}$
\end{tabular}

Sumber: Data primer, 2020. 


\section{Faktor-Faktor Yang Mempengaruhi Eksistensi Kerja Pandai Besi Tradisonal} dalam Menghadapi Era Industri.

Tabel 5 Tanggapan Responden Terhadap Produk

\begin{tabular}{cccccc}
\hline No & Pertanyaan & Ya & $\begin{array}{c}\text { Presentase } \\
(\mathbf{\%})\end{array}$ & Tidak & $\begin{array}{c}\text { Presentase } \\
(\mathbf{\%})\end{array}$ \\
\hline $\mathbf{1} \quad \begin{array}{c}\text { Apakah musiman } \\
\text { produk mempengaruhi } \\
\text { peningkatan produk? }\end{array}$ & 74 & 100 & 0 & 0 \\
$\mathbf{2} \quad \begin{array}{c}\text { Apakah kualitas yang } \\
\text { kuat mempengaruhi } \\
\text { peningkatan produk? } \\
\text { Apakah Eksistensi }\end{array}$ & 74 & 100 & 0 & 0 \\
$\mathbf{3} \quad \begin{array}{c}\text { ukuran produk sesuai } \\
\text { dengan keinginan } \\
\text { konsumen? }\end{array}$ & 74 & 100 & 0 & 0 \\
$\mathbf{4} \quad \begin{array}{c}\text { Apakah warna karat } \\
\text { mempengaruhi } \\
\text { kualitas produk? }\end{array}$ & 15 & 20 & 59 & 80 \\
\hline
\end{tabular}

Sumber: Data Primer diolah 2020

Tabel 6 Tanggapan Responden Terhadap Produk

\begin{tabular}{|c|c|c|c|c|c|}
\hline No & Pertanyaan & Ya & $\begin{array}{c}\text { Presentase } \\
(\%)\end{array}$ & Tidak & $\begin{array}{c}\text { Presentase } \\
(\%)\end{array}$ \\
\hline 1 & $\begin{array}{c}\text { Apakah Bapak } \\
\text { melakukan pemasaran } \\
\text { di tempat pandai besi? }\end{array}$ & 55 & 74 & 19 & 26 \\
\hline 2 & $\begin{array}{c}\text { Apakah Bapak } \\
\text { melakukan promosi di } \\
\text { pasar tradisional? }\end{array}$ & 74 & 100 & 0 & 0 \\
\hline 3 & $\begin{array}{l}\text { Apakah dengan } \\
\text { adanya Era Revolusi } \\
\text { mempengaruhi } \\
\text { Peningkatan promosi } \\
\text { pandai besi? }\end{array}$ & 37 & 50 & 37 & 50 \\
\hline 4 & $\begin{array}{l}\text { Apakah pemasaran di } \\
\text { luar daerah/ Kota } \\
\text { mempengaruhi ke } \\
\text { beradaan kerja pandai } \\
\text { besi dalam memasuki } \\
\text { Era Revolusi } \\
\text { industry? }\end{array}$ & 50 & 68 & 24 & 32 \\
\hline
\end{tabular}

Sumber: Data Primer diolah 2020 
Tabel 7 Tanggapan Responden Terhadap Harga

\begin{tabular}{|c|c|c|c|c|c|}
\hline No & Pertanyaan & Ya & $\begin{array}{c}\text { Presentase } \\
(\%)\end{array}$ & Tidak & $\begin{array}{c}\text { Presentase } \\
(\%)\end{array}$ \\
\hline 1 & $\begin{array}{c}\text { Apakah harga } \\
\text { mempengaruhi } \\
\text { eksistensi kerja pandai } \\
\text { besi dalam memasuki } \\
\text { era revolusi industry? }\end{array}$ & 74 & 100 & 0 & 0 \\
\hline 2 & $\begin{array}{l}\text { Apakah harga yang } \\
\text { relative murah yang di } \\
\text { tawarkan } \\
\text { mempengaruhi } \\
\text { keberadaan pandai } \\
\text { besi dalam memasuki }\end{array}$ & 60 & 81 & 14 & 19 \\
\hline 3 & $\begin{array}{c}\text { Era Revolusi Industri? } \\
\text { Apakah penambahan } \\
\text { pengkereditan } \\
\text { mempengaruhi } \\
\text { pengembangan usaha } \\
\text { pandai besi terhadap } \\
\text { meningkatkan } \\
\text { Eksistensi kerja di Era } \\
\text { Revolusi? }\end{array}$ & 44 & 59 & 30 & 41 \\
\hline
\end{tabular}

Sumber: Data Primer diolah 2020

Tabel 8 Tanggapan Responden Terhadap Teknologi

\begin{tabular}{|c|c|c|c|c|c|}
\hline No & Pertanyaan & Ya & Tidak & Jumlah & $\begin{array}{c}\text { Presentasi } \\
(\%)\end{array}$ \\
\hline 1 & $\begin{array}{c}\text { Apakah peralatan } \\
\text { yang Tradisional } \\
\text { dapat meningkatkan } \\
\text { eksistensi kerja pandai } \\
\text { besi dalam } \\
\text { menghadapi Era } \\
\text { Revolusi }\end{array}$ & 64 & 92 & 5 & 8 \\
\hline 2 & $\begin{array}{l}\text { Apakah Teknologi } \\
\text { seperti HP dapat } \\
\text { meningkatkan } \\
\text { eksistensi pandai besi } \\
\text { dalam menghadapi } \\
\text { Era Revolusi }\end{array}$ & 60 & 81 & 14 & 19 \\
\hline
\end{tabular}

Sumber: Data Primer diolah 2020 


\section{Pembahasan}

Berdasarkan hasil penelitian di atas di lakukan penarikan kesimpulan atas eksistensi kerja pandai besi tradisional dalam memasuki era revolusi industri di kabupaten sidenreng rappang, adapun hasil kajian sebagai berikut:

\section{Krakterstik Kerja Pandai Besi Tradisional di Kabupaten Sidenreng Rappang}

a. Umur

Hasil pada penelitian ini menunjukkan bahwa pengaruh umur terhadap krakteristik kerja pandai besi di kabupaten sidenreng rappang sanggat berpengaruh. Sebagaimana di kemukakan oleh (amron, 2009) mengatakan semakin bertambah umur semakin produktif karena dianggap memiliki penggalaman kerja yang lebih banyak di banding yang masih mudah, kecuali tenaga kerja yang memasuki panga pension atau lanjut usia. Dengan demikin, umur memiliki pengaruh positif terhadap krakteristik kerja pandai besi.

b. Jenis Kelamin

Pengaruh jenis kelamin terhadap krakteristikkerja pandai besi di kabupaten Sidenreng Rappang sangat berpengaruh karena laki-laki memiliki peran tinggi dalam melakukan kerajinan pandai besi dan memiliki peran tinggi untuk bertanggung jawab terhadap kesejahtran keluarga. Sebagaimana di kemukakan oleh (Siahaan, 2003) mengatakan di Indonesia, budaya patriaki mengasumsikan laki-laki menjadi pemimpin dan pembuat keputusan utama, di arena baik public maupun domestic. Mareka dianggap bertanggung jawab terhadap kesejahtran keluarga.

c. Masa Kerja

Pengaruh masa kerja terhadap krakteristik kerja pandai besi di kabupaten sidenrengrappang sangat berpengaruh. Di mana semakin banyak pengalaman kerja tenaga kerja akan menjadi indikasi untuk bertambahnya produktivitas tenaga kerja karena tenaga kerja yang memiliki banyak pengalaman cenderung mempunyai keterampilan dan keahlian dibanding dengan pengalaman kerjanya kurang (Rahmi 2019).

Sebagaimana dikemukakan oleh siangian (2008) menyatakan bahwa masa kerja menunjukkan berapa lama seseorang bekerja pada masing-masing pekerjaan atau jabatan. Hasil ini mendukung teori Robbins (2007), mengemukakan, 'we can say a positive relationship between tenure and job productivity" yang memiliki arti bahwa masa kerja dan produktivitas pekerjaan berhubungan positif. Nyoman ayu adiati (2013) mengatakan bahwa pengalaman kerja berpengaruh secara positif dan signifikan terhadap produktivitas tenaga kerja.

d. Pendapatan

Pendapatan memiliki pengaruh terhadap krakteristik kerja pandai besi di kabupaten sidenrengrappang sesuai yang di kemukakan oleh Uci (2019) dimana variable pendapatan dan jumlah tanggungan keluarga berpengaruh secara simultan atau bersama-sama terhadap konsumsi rumah t.angga pelaku usaha pandai besi di Kelurahan Massepe Kabupaten Sidenreng Rappang.

\section{Faktor-Faktor Yang Mempengaruhi Eksistensi Kerja Pandai Besi Tradisonal dalam Menghadapi Era Industri.}

Hasil temuan penelitian menunjukkan bahwa faktor-faktor yang mempengaruhi eksistensi kerja pandai besi tradisional dalam menghadapi era industri yaitu:

a. Produk

Produk yang di hasilkan oleh perajin usaha pandai besi tradisional sangat berpengaruh secara nyata terhadap peningkatan produk baik dalam bentuk musiman, kualitas yang kuat, 
ukuran yang sesuai dengan konsumen dan warna yang berkarat tidak terlalu memberikan pengaruh terhadap peningkatan produk.

Sebagaimana yang dikemukakan oleh Nur Ajeni (2014) produk yang di hasilkan oleh perajin usaha pandai besi tradisional berpengaruh secara nyata terhadap pendapatan keluarga usaha pandai besi secara signifikan dimana pengaruhnya adalah positif karena produk yang di hasilkan seperti alat-alat pertanian dan lain-lain memiliki kualitas yang bagus, dari segi warna, bentuk dan ukuran sesuai dengan yang diinginkan oleh konsumen.

b. Promosi

Hasil penelitian menunjukkan bahwa parah pengrajin pandai besi dalam melakukan promosi di pasar terdisonal memberikan pengaruh yang besar, pemasaaran di tempat pandai besi sengat memberikan pengaruh, dengan adanya pemasaran di luar daerah/kota sangat memeberikan pengaruh terhadap ke beradaan kerja pandai besi dalam memasuki era revolusi industry, dan dengan adanya era revolusi di tengah-tengah pandai besi pengaruhnya tidak terlalu Nampak melainkan netral.

Sebagaimana yang dikemukakan oleh Nur Ajeni (2014) promosi yang dilakukan oleh perajin usaha pandai besi berpengaruh secara nyata terhadap perkembangan usaha pandai besi dalam pendapatan keluarga secara signifikan dimana pengaruhnya adalah positif dimana promosi bertambah baik, misalnya dengan pemasaran keliling dan pemasaran kepasar-pasar maka pendapatan keluarga setiap bulannya akan mengalami peningkatan atau penambahan. c. Harga

Hasil penelitian menunjukkan bahwa harga yang relative murah sangat memberikan pengaruh dalam eksistensi kerja pandai besi dalam memasuki era revolusi, dan adapun penambahan pengkereditan memberikan pengembangan usaha pandai besi di Sidenreng Rappang.

Sebagaimana yang dikemukakan oleh Nur Ajeni (2014) harga yang di jual berpengaruh secara nyata terhadap pengembangan usaha pandai besi terhadap pendapatan keluarga secara signifikan, dimana pengaruhnya adalah positif, karena harga yang relatif terjangkau dan ada garansi dan penambahan pengkereditan jangka waktu satu bulan dalam pengkeritan hasil perajin pandai besi tradisional. Hal ini juga menambahkan bahwa hipotesi yang di ajukan dalam penelitian ini dapat diterima.

d. Teknologi

Hasil penelitian menunjukkan bahwa teknologi dalam hal pemasaran hasil kerja pandai besi melalui media aplikasi Hp memberikan pengaruh, sedangkan dalam alat yang di gunakan saat ini masih tradisional sehingga alat yang lebih canggih tidak memberikan pengaruh yang sangat besar.

\section{Bagaimana Pandai Besi Tradisional Bisa Bertahan di Era Revolusi Industri di Kabupaten Sidenreng Rappang.}

Produk pandai besi bisa bertahan di massepe karena memiliki beberapa keunggulan seperti bentuk dan ketahanan yang khas dari produksi barang tersebut, harga yang terjangkau, serta ketersedian di daerah itu sendiri dan mudah di jangkau bagi masyarakat sekitar.

\section{SIMPULAN DAN SARAN}

Berdasarkan hasil penelitian yang telah dilakukan tentang Eksistensi kerja pandai besi tradisional di era revolusi industri di kabupaten sidenreng rappang, maka dapat disimpulkan bahwa:

1. Kerakteristik kerja pandai besi tradisional di sidenreng rappang terdiri atas pekerja dengan rentang usia 20 hingga 50 tahun keatas di mana pekerja terbanyak berada pada rentang usia 50 tahun ke atas. Pekerja pandai besi yang diwawancarai seluruhnya berjenis kelamin laki- 
laki. Umumnya para pekerja pandai besi bekerja pada hari senin-sabtu pada pukul 08.0016.00. penghasilan yang didapatkan bervariasi namun berdasarkan hasil wawancara mayoritas pekerja memiliki penghasilan sebesar Rp. 500.000,00-Rp. 2. 500.000,00.

2. Faktor-faktor yang mempengaruhi eksistensi kerja pandai besi tradisional dalam menghadapi era industri diantaranya adalah produk

3. Cara pandai besi bertahan di era revolusi industri di kabupaten sidenreng rappang yaitu dengan mempertahankan bentuk dan ketahanan yang khas dari produksi barang tersebut, serta memiliki harga jual yang terjangkau, dan ketersedian di daerah itu sendiri sehinga mudah di jangkau bagi masyarakat sekitar.

Diharapkan kepada pemerintah daerah, dinas perindustrian, pemerintah terkait ketenagakerjaan untuk sering mengadakan pelatihan dan pembinaan khususnya terhadap tenaga kerja pandai besi yang ada di Kabupaten Sidenreng Rappang agar memilki peningkatan produktivitas, mempunyai daya jual tinggi dan mampu bersaing dengan produk industri besar yang sejenis.

Agar terbina jasa entrepreneur serta peningkatan pendapatan para tenaga kerja pandai besi di harapkan jangan bergantung kepada pesanan para pengusaha, mereka harus bisa mengelolah dan menjual hasil produksinya sendiri sehingga dengan menjual hasil produksi sendiri akan meningkatkan pendapatan yang jauh lebih tinggi.

\section{DAFTAR PUSTAKA}

Badan Pusat Statistik. 2017. Sidenreng Rappang Dalam Angka. Badan Pusat Statistik: Sidrap. Graham, Helen.2005. The Human Face of Psychology: Humanistic Psychology in its Historical, Social and Cultural Context. Pustaka Pelajar. Yogyakarta.

Rahmi, 2018. Analisis Faktor Yang Mempengaruhi Produktivitas TenagaKerja Pandai Besi di Kabupaten Sidenreng.

Rickho, Vorta. 2009. Eksistensi Bisnis Etnis Tionghoa - Studi Deskriptif Terhadap Pedagang Etnis Cina Penjual Spare Part Sepeda Motor Di kelurahan Kampung Baru, Kecamatan Medan, Maimun. Fisip USU, Medan. (Skripsi, Tidak diterbitkan).

Sugiyono. 2006. Statistika Untuk Penelitian. Cetakan Kesembilan. Alfabeta: Bandung. 